\title{
The effect of rolling resistance on people's willingness to cycle during wintertime
}

\author{
Mathis Dahl Fenre ${ }^{*}$ (D) and Alex Klein-Paste
}

\begin{abstract}
Harsh winters reduce utilitarian cycling in many cities. Using an online survey, we examined how increasing rolling resistance due to snow and ice affect people's cycling willingness. The respondents $(N=1318)$ reported their willingness to cycle on various winter cycling conditions presented in photos. The answers were compared to the rolling resistance levels on the presented conditions, measured in a previous study. Respondents' cycling willingness dropped from $91.2 \%$ at very low to $18.3 \%$ at very high rolling resistances. The cyclist's age, gender, local climate, winter cycling experience and studded tire use affected the cycling willingness significantly. Electric bike usage did not affect cycling willingness. "Summer-only" cyclists did not cycle during the winter due to low temperatures (29\%), lacked feeling of safety (27\%), bicycle wear (17\%), increased travel time (17\%) and increased physical effort (10\%). Hence, lower rolling resistance and increased use of studded tires can increase the cycling frequency of existing winter cyclists. To recruit new winter cyclists, the surface conditions should not only offer a low rolling resistance but should also be perceived as safe and comfortable.
\end{abstract}

Keywords: Sustainable transportation, Winter cycling, Cycling willingness, Rolling resistance, Winter maintenance

\section{Introduction}

The number of both recreational and utilitarian bicycle trips often drops significantly during the winter months. This is especially the case in the Nordic countries $[1,6$, $15,40]$ and some parts of Northern America with harsh winters [3, 21, 42, 46]. Fournier et al. [22] found that in areas with harsh winters (in the northern hemisphere), the seasonal bicycle usage can be estimated with a sinusoidal model peaking on July 1 and being at the minimum on January 1. The most prominent "barriers" to winter cycling have been identified to be cold temperatures, increased precipitation, darkness and inclement road conditions $[6,8,26,36,48]$.

There is a widespread political desire to increase bicycle usage throughout the year because it can relieve the pressure on overcrowded metros and buses [49]. More cycling also leads to benefits in terms of public health, travel-time reliability, cost-effectiveness, reduced

* Correspondence: mathis.fenre@ntnu.no; mdfenre@gmail.com NTNU Norwegian University of Science and Technology, Institute of Civil and Environmental Engineering, Hoegskoleringen 7a, 7034 Trondheim, Norway congestion and pandemic resilience [7, 20, 30, 33, 52]. Due to the acknowledged benefits, several governments have set official goals for increased cycling. The current Norwegian National Transport Plan (2018-2029) states that walking and cycling should cover $40-60 \%$ of all passenger traffic increases in urban areas [39]. Finland's new energy and climate strategy include an official national goal to increase the number of trips made by bicycle or foot to $30 \%$ by 2030 [29]. Sweden published a national strategy dedicated to more and safer cycling and invested 100 million SEK in promoting cycling in a 2016-2017 initiative [47]. Malone [34] analyzed cycling policies that have been deployed in several European cities in a report produced for EU city planners, decisionmakers and citizens. The report underlines that a successful cycling policy can only be achieved by an organization with knowledge and cycling data. Malone indicates that municipalities should build this knowledge by developing relationships with engineering firms, schools, cycling associations and consultants.

The goal of deploying cycling policies is to increase cycling by inducing changes in the factors determining 
people's cycling habits, i.e., cycling determinants. Previous research has documented these factors thoroughly. Pucher and Buehler [44] summarize the majority of academic research on how to increase cycling in cities and make it safer for all society segments. Heinen et al. [28] present a comprehensive review of the academic literature on the dominant factors affecting people's decision to cycle or not. To summarize, the cycling determinants can be divided into four main categories, namely the natural environment (weather and topography), the built environment (infrastructure and land-use mix), temporal factors (calendar-events and time of day), and other (individual and cultural) factors. An et al. [4], Butterworth and Pojani [9], Schneider [45], Willis et al. [56] have later written complementary overviews on this topic.

To increase cycling, one can induce changes in the cycling determinants to either recruit new cyclists or increase current cyclists' cycling frequency. To recruit new cyclists, there is often a need to reduce cultural or personal barriers such as a negative attitude towards cycling or work and family commitments. Occasional cyclists are often reluctant to increase their cycling frequency due to flexibility and practical matters, for example, if they need to transport cargo during the day [23]. Moreover, to encourage summer cyclists to cycle more during the winter, proper winter maintenance, especially snow removal, is essential $[6,37,50,51]$. However, to evaluate the cost-benefit of improved winter maintenance, there is still a need for more knowledge about the actual effect of improved winter maintenance [55].

The purpose of winter maintenance is to improve the road surface conditions. During the winter, snow and ice on the roads often reduce skid resistance and steerability and increase cycling resistance and unevenness. Quantifiable surface quality measurements are important to evaluate the effect of winter maintenance performances on infrastructure winter resilience [57]. Friction measurements have been used to quantify the skid resistance, and an adequate friction level is essential for cycling safety [37, 38].

Another quantifiable measure of the surface conditions is rolling resistance. The rolling resistance increase with increasing loose snow depths and unevenness $[13,19,32$, 54]. The rolling resistance is also highly dependent on the bicycle properties, i.e., tire rubber properties, inflation pressure and contact area [12, 24]. Previous research has found a nearly linear relationship between wheel load, i.e., the average contact pressure times the contact area between the wheel and the road surface, and rolling resistance force [5, 11, 24, 25]. The coefficient of rolling resistance, $\mathrm{C}_{\mathrm{rr}}$, has therefore been established to compare rolling resistances for different wheel loads:

$$
C_{r r}=\frac{F_{r}}{F_{N}}
$$

where $F_{r}$ is the rolling resistance force and $F_{N}$ is the wheel load.

Fenre and Klein-Paste [18] developed a new method for estimating bicycle rolling resistance on cycleways by measuring propulsive and resistive forces on a moving bicycle. This method considers pedaling power, air drag forces, inertial forces, and gravity forces. The method is suitable for rolling resistance measurements at variable speeds, variable weather conditions, and any road gradient. This method was utilized to investigate how bicycle rolling resistance is affected by typical winter conditions on cycleways. These investigations found a strong correlation between the rolling resistance level and snow type, loose snow depth, and unevenness [19]. Moreover, there seems to be knowledge gap about how the rolling resistance level correlates to people's willingness to cycle. This knowledge can help determine how various winter maintenance actions affect the urban infrastructure resilience during wintertime.

In this study, we used an online survey to collect data about people's willingness to cycle on various winter cycling conditions shown in photos. We compared the cycling willingness results to rolling resistance measurements of the same conditions collected in a previous study [19] and investigated how people's stated willingness to cycle is affected by the rolling resistance level.

\section{Method \\ Data collection}

The data in this study was collected during May 2020 through an online survey. The participants were mostly recruited through Facebook. Invitations to the survey were shared in several cycling-affiliated groups, in groups for environmental organizations and Norwegian municipalities' Facebook-groups. The survey was also shared through the authors' private Facebook accounts and via e-mail and internal network channels to the Department of Civil and Environmental Engineering at NTNU and the Norwegian Public Roads Administration (NPRA).

The survey included socio-demographic questions to map the participant's age, gender and location (county). The participants' ages were sorted into six age groups: under 18,18 to 35,36 to 50,51 to 65 over 65 years old. The participants' locations were sorted by the Norwegian main geographical regions: North, Middle, West, East and South. As most utilitarian cycling occurs in urban areas, we chose to collect climate data from the largest cities in each region as reference points to analyze the effect of climate on cycling. Figure 1 shows Norway's location in Europe, the Norwegian geographical regions and the largest cities in each region. Table 1 shows climatic data for these cities during the winters (October-March) of 2010-2020. 


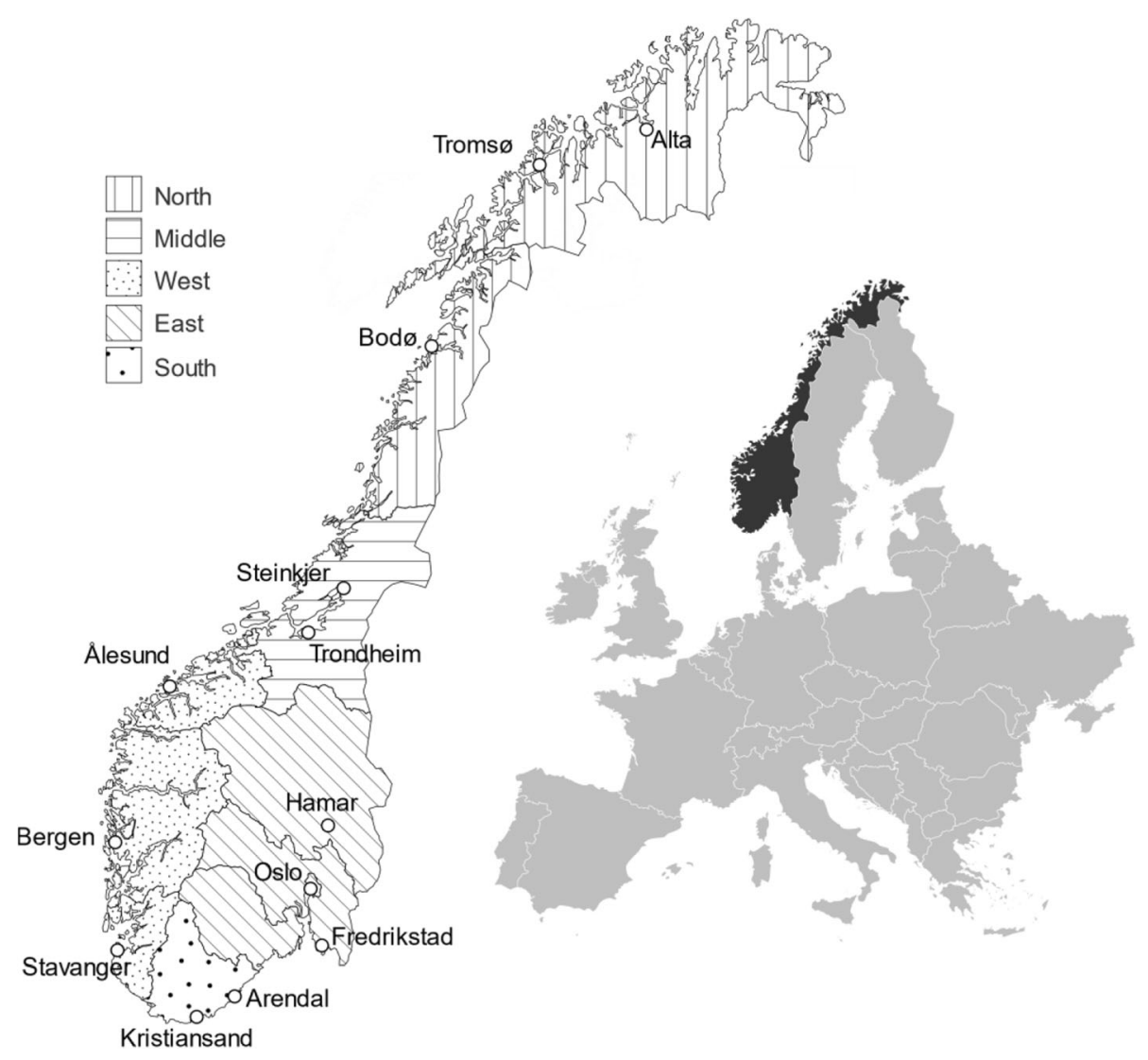

Fig. 1 Map illustrating Norway's location in Europe, the main Norwegian geographical regions and their largest cities

There were also questions mapping how often the participants cycle during the summer (April-September) and how often they cycle during the winter (OctoberMarch). Those respondents who answered that they cycle during the winter (the winter cyclists) were asked what type of bicycle they usually use when cycling during the winter. The winter cyclists were also asked whether they normally use studded tires when cycling during the winter. Those who answered that they cycle during the summer but not during the winter (summer only cyclists) were asked to specify the reason for not cycling during the winter. For this question, there were five alternatives: 1) it takes too much time; 2) It is too cold; 3) I do not feel safe; 4) It is too tiring; 5) I want to avoid wear and tear on my bicycle. This question was asked to investigate how and to what extent improved winter maintenance may affect summer only cyclists.

The survey's main part contained 37 photos of winter cycling surface conditions collected in January and February of 2019. The photos were collected during rolling resistance measurements on winter conditions using a bicycle steering bar-mounted camera. The photos show various road conditions, including wet asphalt, slush, compact snow, ice, loose snow, and dirt and salt-contaminated snow.
For clarification, a short description of the road conditions was provided for each photo. For each photo, the participants were asked: Are you willing to cycle here? They could choose one out of four alternative answers: A: Not at all; B: A short stretch; C: Large parts of the route; $\mathrm{D}$ : The whole route. The survey did not reveal to the participants the rolling resistance levels on the conditions in the photos. Eight road stretches were shown twice or thrice during the survey, with very similar photos (taken a few meters apart). Respondents who submitted completely different answers on very similar photos were identified as inconsistent and removed from the results.

The survey photos were snapshots from video recordings captured during an earlier study where rolling resistance was measured on various winter cycling conditions. The rolling resistance was estimated using an instrumented bicycle that measured propulsive and resistive forces acting on the moving bicycle. The instrumented bicycle had sensors measuring pedaling power, airspeed, velocity and road gradient. The rolling resistance was found by solving the force equilibrium on the moving bicycle. The rolling resistance measurement method is described in detail in Fenre and Klein-Paste 
Table 1 Mean annual snowfall, snow days (days with snow precipitation) and mean temperature from October to March for the years 2010-2020 for the largest cities in each of Norway's main geographical regions [53]

\begin{tabular}{|c|c|c|c|c|c|c|c|c|c|}
\hline \multirow[t]{2}{*}{ Region } & \multirow[t]{2}{*}{ City } & \multirow{2}{*}{$\begin{array}{l}\text { Mean annual } \\
\text { snowfall }(\mathrm{cm})\end{array}$} & \multirow{2}{*}{$\begin{array}{l}\text { Mean annual } \\
\text { snow days }\end{array}$} & \multicolumn{6}{|c|}{ Mean temperature $\left({ }^{\circ} \mathrm{C}\right)$} \\
\hline & & & & Oct & Nov & Dec & Jan & Feb & Mar \\
\hline \multirow[t]{2}{*}{ South } & Kristiansand & 74.6 & 11.3 & 8.3 & 4.0 & 1.1 & -0.8 & -0.2 & 2.7 \\
\hline & Arendal & 103.9 & 15.5 & 9.5 & 5.4 & 2.9 & 0.7 & 0.6 & 3.0 \\
\hline \multirow[t]{3}{*}{ East } & Fredrikstad & 60.7 & 13.2 & 8.9 & 4.5 & 1.6 & -1.1 & -0.7 & 2.2 \\
\hline & Oslo & 115.4 & 23.4 & 6.8 & 2.2 & -1.3 & -3.3 & -2.0 & 1.8 \\
\hline & Hamar & 101.7 & 25.1 & 5.2 & 0.1 & -4.5 & -6.9 & -5.1 & -0.8 \\
\hline \multirow[t]{2}{*}{ Middle } & Trondheim & 130.7 & 26.1 & 6.0 & 1.7 & -0.6 & -2.2 & -1.0 & 1.0 \\
\hline & Steinkjer & 142.8 & 29.6 & 5.6 & 1.7 & -1.0 & -3.1 & -1.9 & 0.4 \\
\hline \multirow[t]{3}{*}{ West } & Stavanger & 28.8 & 5.4 & 9.2 & 5.8 & 3.7 & 1.9 & 2.0 & 3.8 \\
\hline & Bergen & 76.7 & 11.3 & 9.0 & 5.3 & 3.4 & 1.8 & 2.3 & 4.0 \\
\hline & Ålesund & 76.3 & 10.1 & 8.4 & 5.4 & 3.8 & 2.8 & 2.8 & 4.4 \\
\hline \multirow[t]{3}{*}{ North } & Bod $\varnothing$ & 147.0 & 27.7 & 6.0 & 2.9 & 1.0 & -1.3 & -0.8 & 0.3 \\
\hline & Troms $\varnothing$ & 275.2 & 44.9 & 3.5 & 0.5 & -1.4 & -3.7 & -3.3 & -2.0 \\
\hline & Alta & 189.3 & 48.8 & 2.7 & -2.3 & -4.5 & -8.1 & -7.2 & -3.7 \\
\hline
\end{tabular}

[19]. Thus, each survey photo had a corresponding rolling resistance level. In the survey, the photos were shown in a random rolling resistance order. The full survey, answers, photos and rolling resistance data are available as an online dataset [16].

\section{Data analyses}

In the data analyses, the survey data was combined with the rolling resistance data. The cycling willingness answers were sorted after rolling resistance levels on the conditions in the photos and placed into six rolling resistance level ranges going from $C_{r r}=0.00$ to $C_{r r}=0.06$. Table 2 shows the mean and standard deviation of the measured rolling resistance in each group, as well as three example photos of the road conditions in each group. Exploratory data analyses were used to discover differences in cycling willingness for different rolling resistance groups between different participant groups. To test whether the differences observed in the exploratory analyses were significant between the answers from different age, location and cycling frequency groups, we utilized a Kruskal-Wallis one-way analysis of variance test. The Kruskal-Wallis test is a nonparametric method for testing whether samples originate from the same distribution [31]. If the Kruskal-Wallis test indicated that the distribution of some groups significantly differed from the others, a Dunn's post hoc test for multiple comparisons of mean rank sums was performed to identify which groups differed from each other [14]. A Mann-Whitney u-test was used to find significant differences between opposite groups: female or male, electric bike (e-bike) or not and studded tires or not. The Mann-Whitney $\mathrm{u}$-test is a nonparametric test of the null hypothesis that, for randomly selected values $\mathrm{x}$ and $\mathrm{y}$ from two populations, the probability of $x$ being greater than $y$ is equal to the probability of $y$ being greater than $x$ [35]. The statistical tests were performed with a significance level, $\alpha=0.05$. To limit the relative size difference between the groups in the statistical analyses, groups with less than $N=40$ respondents were excluded.

\section{Results}

The survey received a total of 1318 complete responses. Thirty responses were filtered out due to inconsistency. The respondents reside all over the country with a predominance of people from the eastern and middle part. The survey had more male (79\%) than female (31\%) respondents. The largest part of respondents was in the age group from 36 to 50 years old (45\%). The age groups from 18 to $35(24 \%)$ and 51 to 65 years old (30\%) and were also well represented. The age groups 66 to 75 and more than 75 years old were combined and represented $2 \%(N=31)$ of the respondents. The respondents younger than 18 were excluded from the statistical analyses due to a small sample size $(N=9)$.

$7 \%$ of the respondents answered that they were "summer only" cyclists. Only $1 \%(N=19)$ were not cyclists at all. $92 \%$ responded that they are winter cyclists, meaning that they use a bicycle for utilitarian purposes more than once per month during the winter. $76 \%$ stated that they cycle several times per week during the winter. Out of the winter cyclists, $26 \%$ answered that they mostly use ebike when cycling in the winter months. This is more than the e-bike share rate for Norway as a whole (15\%) [41]. $89 \%$ of the winter cyclists responded that they normally use studded tires during the winter months. 
Table 2 Example photos of road conditions providing six ranges of bicycle rolling resistance. Mean measured rolling resistance and \pm standard deviation in parentheses
$\mathrm{C}_{\mathrm{rr}}$ level 1: $0.00<\mathrm{C}_{\mathrm{rr}} \leq 0.01(0.0075 \pm 0.0019) . \mathrm{N}=4$
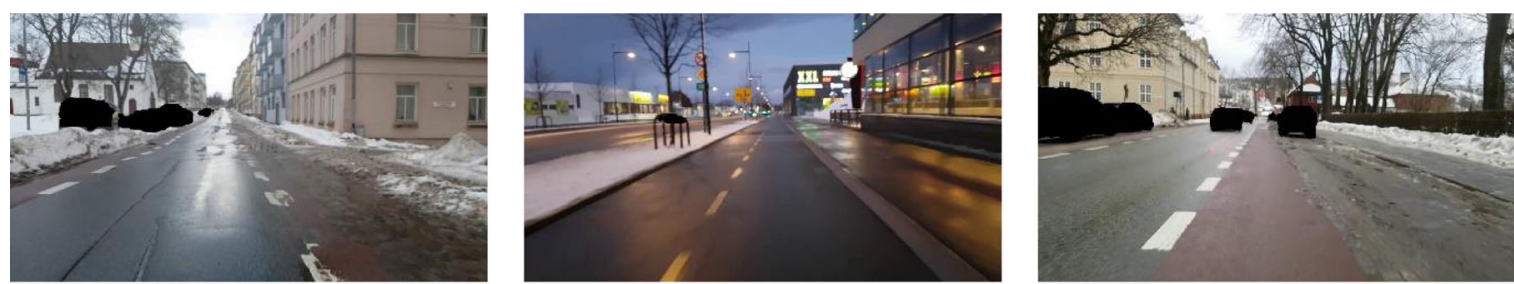

$\mathrm{C}_{\mathrm{rr}}$ level 2: $0.01<\mathrm{C}_{\mathrm{rr}} \leq 0.02(0.0136 \pm 0.0022) . \mathrm{N}=8$
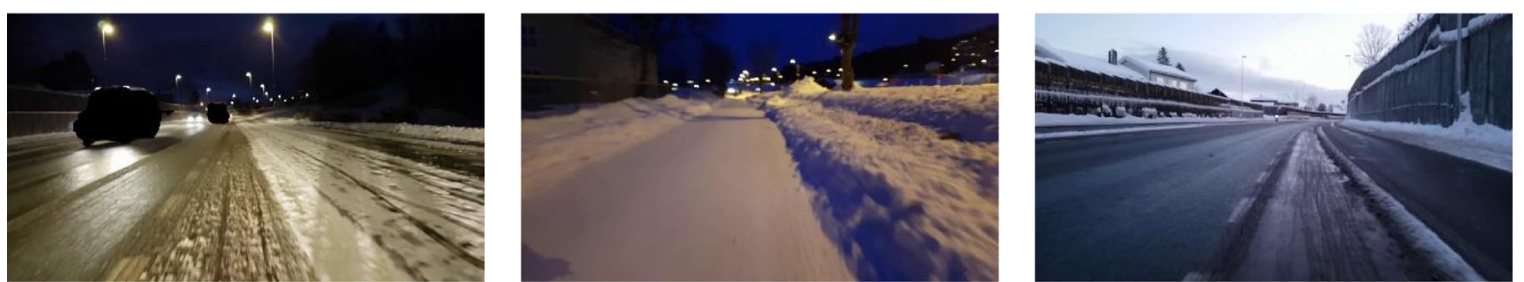

$\mathrm{C}_{\text {rr }}$ level 3: $0.02<\mathrm{C}_{\text {rr }} \leq 0.03(0.0269 \pm 0.0024) . \mathrm{N}=9$
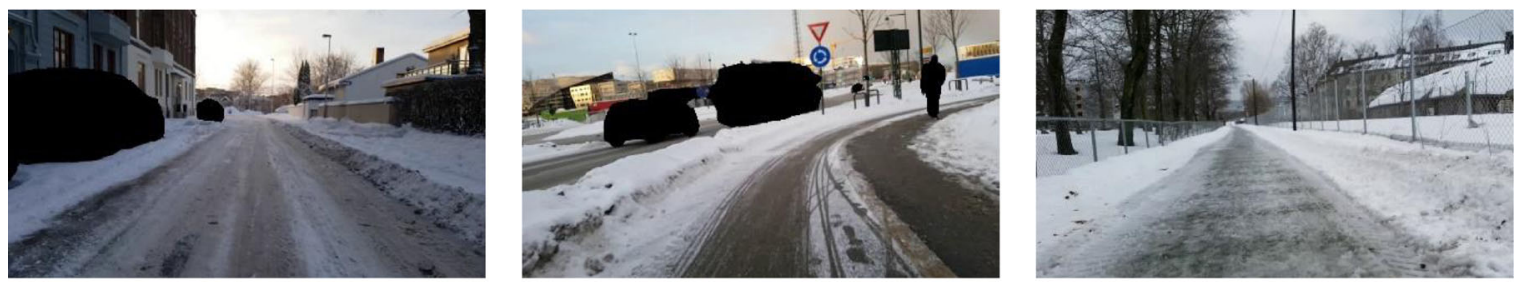

$\mathrm{C}_{\mathrm{rr}}$ level 4: $0.03<\mathrm{C}_{\mathrm{rr}} \leq 0.04(0.0377 \pm 0.0017) . \mathrm{N}=7$
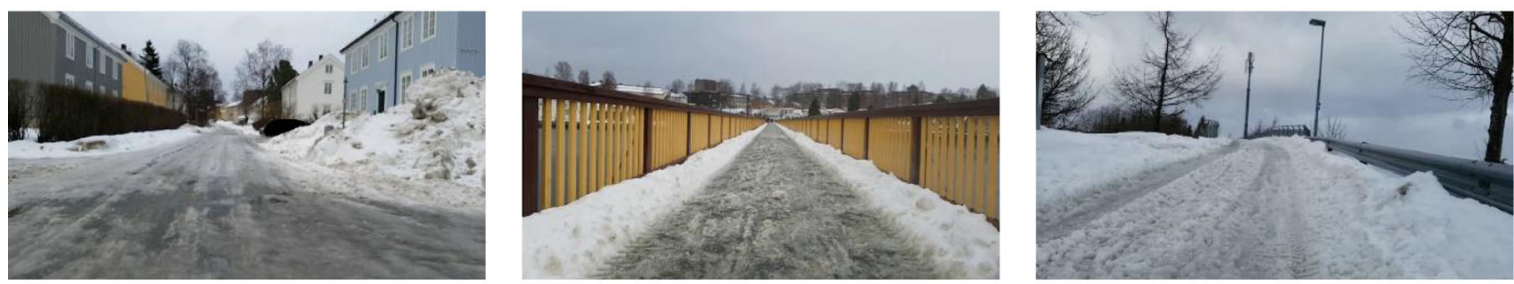

$\mathrm{C}_{\mathrm{rr}}$ level 5: $0.04<\mathrm{C}_{\mathrm{rr}} \leq 0.05(0.0446 \pm 0.0038) . \mathrm{N}=5$
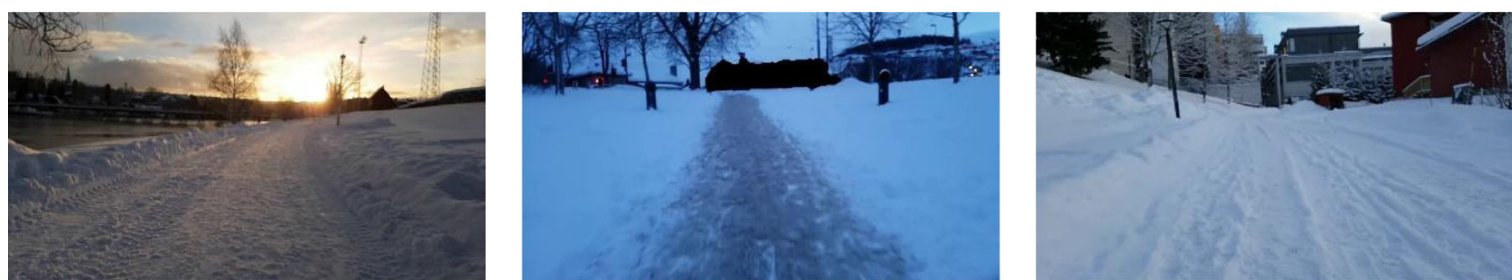

$\mathrm{C}_{\mathrm{rr}}$ level 6: $0.05<\mathrm{C}_{\mathrm{rr}} \leq 0.06(0.0546 \pm 0.0018) . \mathrm{N}=5$
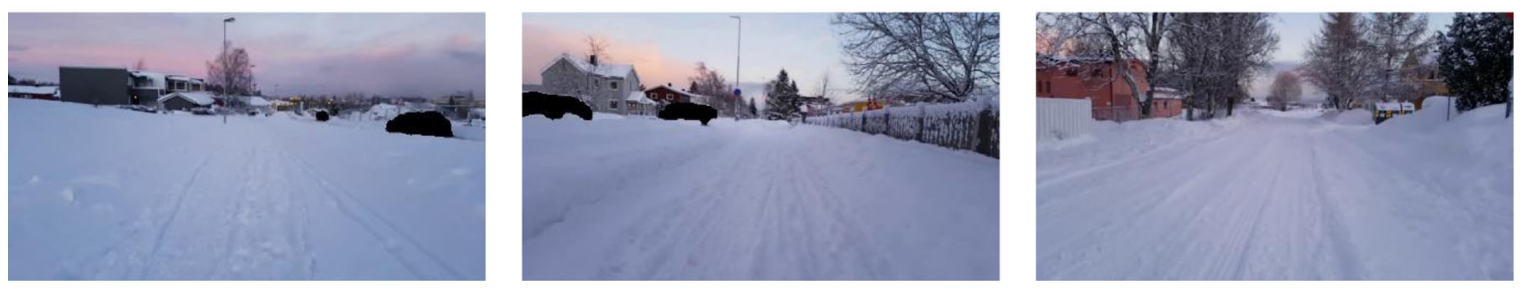
Among the "summer only" and "not at all" cyclists, the reasons for not cycling during the winter were: "It is too cold" (29\%), "I feel unsafe" (27\%), "I want to avoid wear and tear on my bicycle" (17\%), "It takes too long" (17\%) and "It is too tiring" (10\%).

To analyze the respondent's stated willingness to cycle on the survey photos' conditions, we introduce the $c y c$ ling willingness index (CWI). CWI is defined as the percentage of respondents answering: "Large parts of the route" or "The whole route" to the question "Are you willing to cycle here?"

Figure 2 shows CWI plotted against the coefficient of rolling resistance for different respondent groups. Table 3 contains the tabular data for Fig. 2. The figure shows a clear reduction in CWI as the rolling resistance increases. Figure 2a shows that overall, the CWI increases from $25 \%$ at $\mathrm{C}_{\mathrm{rr}} \approx 0.049$ to $50 \%$ at $\mathrm{C}_{\mathrm{rr}} \approx 0.027$ to $75 \%$ at $\mathrm{C}_{\mathrm{rr}} \approx 0.012$ and up to $90 \%$ at $\mathrm{C}_{\mathrm{rr}} \approx 0.008$. A general trend among all respondents is that the reduction of CWI for increasing rolling resistances is rapid at first before the reduction gradually slows down and eventually seems to flatten out at large rolling resistances.

Figure $2 \mathrm{~b}$ shows that male cyclists are less affected by increasing rolling resistance levels than female cyclists. Figure 2c shows that the age group over 65 years old is marginally, yet significantly, more affected by increasing rolling resistance than the rest of the respondents. Figure $2 \mathrm{~d}$ shows that the CWI of people living in northern Norway is significantly less affected by increasing rolling resistance than people living in the rest of the country. Increasing rolling resistance levels affect the CWI of people living in the middle and the eastern part of Norway significantly more. Those most affected are the people living in western Norway. There were not enough respondents from the southern part of Norway $(N=19)$ to find any significant results for this group. Figure 2e shows that yearround cyclists show a significantly higher CWI than summer only cyclists for all rolling resistance values. The most considerable difference in CWI is found at $\mathrm{C}_{\mathrm{rr}}$ values between 0.02 and 0.03 . Figure $2 \mathrm{f}$ shows that people's winter cycling frequency affects their CWI. The cycling willingness is largest for those cycling daily during the winter and decreases gradually for the weekly, monthly, and never winter cyclists. Figure $2 \mathrm{~g}$ shows that CWI of e-bike users are equally affected by increasing $C_{\mathrm{rr}}$ levels as the other bicycle type users. Figure $2 \mathrm{~h}$ shows that cyclists who use studded tires are significantly less affected by increasing rolling resistances than cyclists who do not use studded tires during the winter. The difference is largest at medium-large $\mathrm{C}_{\mathrm{rr}}$ values (between 0.02 and 0.03 ).

\section{Discussion}

The first main finding in this study is that the willingness to cycle during the winter, represented with the cycling willingness index (CWI), decreases significantly with increasing rolling resistances for all respondent groups. This indicates that proper winter maintenance is indeed a key factor in promoting winter cycling, as it is the only way road owners can lower the rolling resistance. Well performed winter maintenance will promote winter cycling in all groups, from the cautious, only cycling sporadically during the summer cyclists to the risktaking, well equipped, enthusiastic winter cyclists. By reducing the $\mathrm{C}_{\mathrm{rr}}$ from $\sim 0.027$ to $\sim 0.008$, one can expect the CWI to increase from $50 \%$ to $90 \%$. This reduction in $\mathrm{C}_{\mathrm{rr}}$ can for example be obtained by going from a cycleway with less than $2 \mathrm{~cm}$ of loose snow on top of a compact snow layer to a cycleway with wet asphalt, completely free from snow [19].

Moreover, the results from this study show that male cyclists are less affected by increasing rolling resistances than female cyclists. This finding correlates with several previous studies. Amiri and Sadeghpour [3] and Heesch et al. [27] found that there are generally more male than female cyclists and that men cycle longer distances than women. Men have also generally been more risk-taking than women. However, this gap seems to grow smaller over time $[2,10]$. Research has also found that men consider cycling more acceptable than women [43].

Figure $2 \mathrm{~d}$ shows that the CWI of respondents living in northern Norway is less affected by increasing rolling resistances than people from the rest of the country. Table 1 shows that northern Norway has been the part of the country with the coldest and snowiest winters. The CWI of people living in western Norway, the region with the warmest and least snowy winters, is most affected by increasing rolling resistances. Therefore, this result indicates that people who are used to harsh winters are less sensitive to increased rolling resistance. This is also reflected in Fig. 2e and f, which shows that frequent winter cyclists are less affected by increasing rolling resistances than less frequent winter cyclists.

When it comes to age, those older than 65 are more affected by increasing rolling resistances than the rest of the respondents. This is probably not only because it is heavier to cycle with increased rolling resistance, but that the older cyclists are more aware of the risks and perceive conditions that have a higher rolling resistance as "less safe". The age group between 18 and 35 is significantly less affected by increasing rolling resistances than those older than 65 . Simultaneously, they are significantly more affected than the respondents between the age of 36 and 65 . This agrees with the analyses by Parkin et al. [43], who found that young people and older people consider the risk of cycling in cities to be higher than those in the age band 35 to 44 years. Why the cyclists aged between 35 and 65 in this study are least affected by increasing rolling resistances can also 


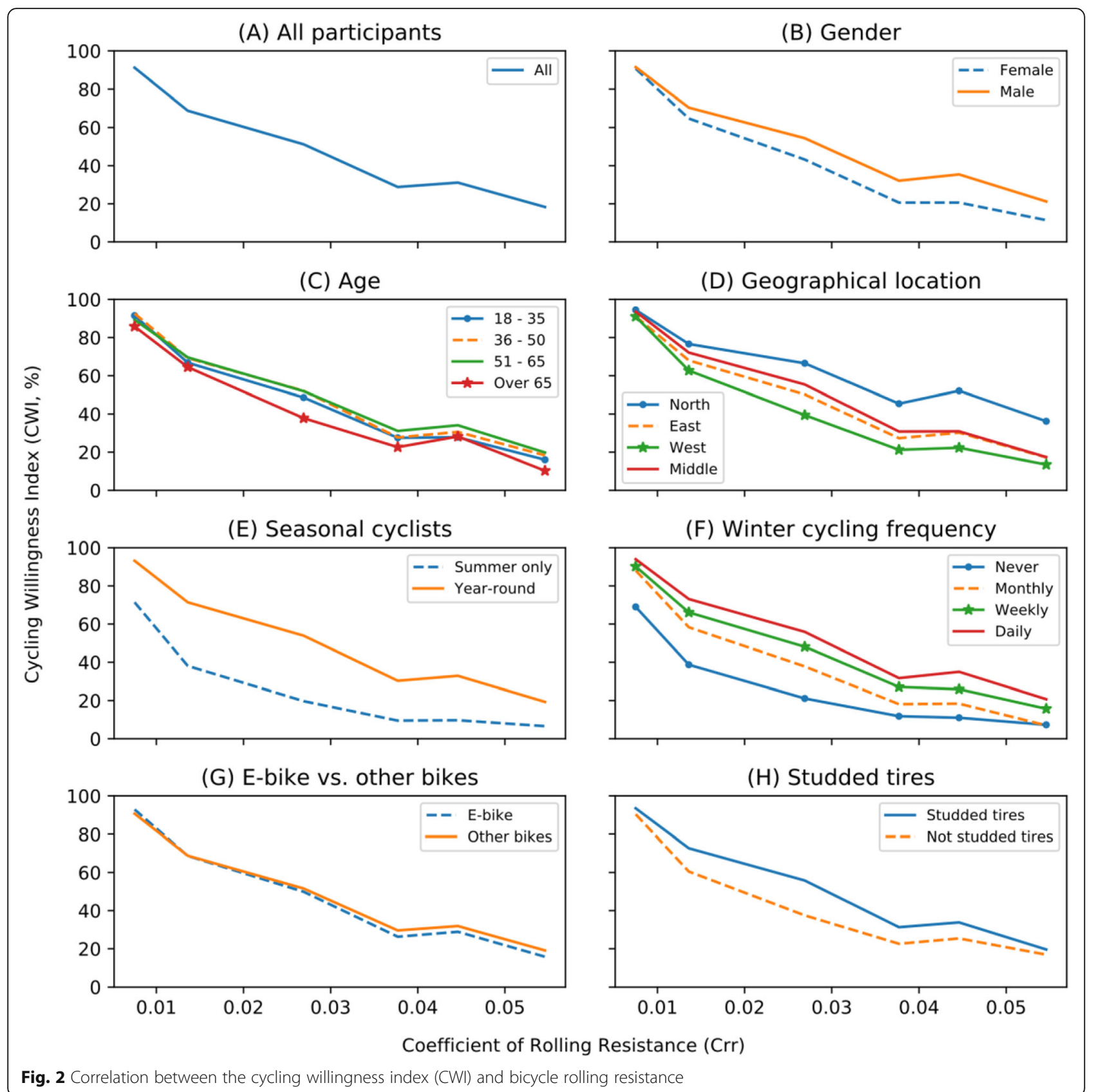

be explained by the differences in CWI for people living in different climatic regions, indicating that cyclists with a vast winter cycling experience are less affected by increased rolling resistances due to snow and ice. However, risk aversion seems to reduce cycling willingness built from cycling experience with age.

Figure $2 \mathrm{~g}$ shows that the CWI of e-bike users and users of other bicycle types are equally affected by increasing rolling resistances. This came as a surprise to the authors because e-bikes reduce the cyclists' effort to overcome increasing rolling resistances. Therefore, we expected that e-bike users' willingness to cycle would be less reduced by increased rolling resistance than cyclists on standard bikes. This contradictory finding suggests that the increased effort needed to overcome larger rolling resistances due to snow and ice is not the main reason why cyclists are less willing to cycle on cycleways with elevated $\mathrm{C}_{\mathrm{rr}}$ levels.

This is also reflected in the observation that only $10 \%$ of the summer only cyclists stated that "because it is too tiring" was the reason why they did not cycle during the winter. The main reasons for not cycling during the winter was that "it is too cold" (29\%) and "I feel unsafe" (27\%). Fenre and Klein-Paste [19] found that an 
Table 3 Cycling willingness index $(\mathrm{CWI})$ for the different coefficient of rolling resistance $\left(\mathrm{C}_{\mathrm{rr}}\right)$ ranges. $P$-value representing the difference between answer distribution for opposite groups. Post-hoc indicates significant differences between answer distribution for multiple groups

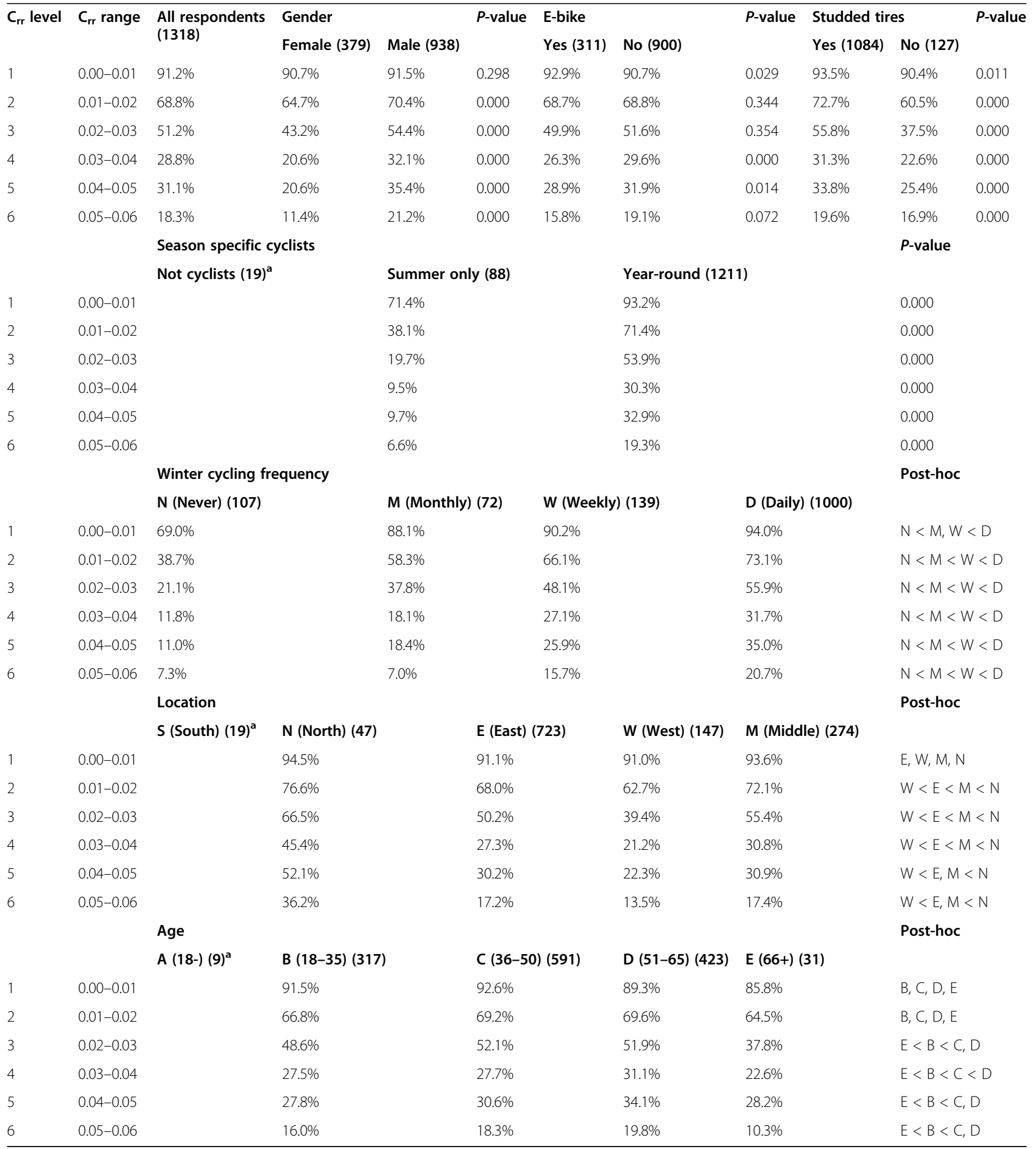

${ }^{\mathrm{a}}$ Groups with $N<30$ : not included in statistical analyses. $P$-value $<0.05$ indicates significant differences between groups

increased rolling resistance during winter cycling was accompanied by reduced steerability and increased unevenness. The reduction in willingness to cycle appears therefore directly related to reduced steerability and increased unevenness (which is close to equal for all bicycle types), rather than that it is harder to cycle. Reduced steerability and increased unevenness will often lead to a reduced feeling of safety when cycling. 
Opposed to e-bike users, cyclists using studded tires during winter show a significantly larger CWI than other cyclists for increasing $\mathrm{C}_{\mathrm{rr}}$ values. Studded tires improve traction on slippery surfaces and facilitate safe cycling. This finding also supports the theory that it is not the need for an increased physical effort that is the main barrier to cycling on cycleways covered in snow and ice, but the reduced feeling of safety. Knowing this, promoting widespread use of studded tires seems to be more effective than promoting e-bike usage when seeking to increase the number of bicycle trips during the winter.

Figure 2 shows that the reduction in CWI is significantly larger, going from very low to low coefficients of rolling resistance $\left(C_{\mathrm{rr}}\right.$ level $1 \rightarrow \mathrm{C}_{\mathrm{rr}}$ level 2$)$ than it is going from large to very large $C_{r r}\left(C_{r r}\right.$ level $4 \rightarrow C_{r r}$ level 6). This means that there are most gains at the lower end of the $C_{\mathrm{rr}}$ range, and one should perform winter maintenance at a very high level to increase winter cycling significantly. Figure $2 \mathrm{e}$ and $\mathrm{f}$ show that to recruit $50 \%$ of the "summer-only" respondents in this study, the rolling resistance level must at most be as low as 0.011 . This rolling resistance level is only offered by snow-free asphalt roads or, in some cases, a smooth, compact snow layer.

Despite the finding that extra physical effort is not the most crucial factor affecting cycling willingness, it seems that rolling resistance measurements can be a suited parameter to quantify the surface conditions. Crr measurements can describe the conditions in a measurable manner that directly relates to peoples' willingness to cycle. It is important to remember that the measurement equipment properties, e.g., the bicycle used to collect Crr measurements, affect the results. Therefore, a comparison of $\mathrm{C}_{\mathrm{rr}}$ data collected with other measurement equipment than that used to collect the data in this study requires instrument calibration.

\section{Conclusions}

This study investigated the correlation between people's stated willingness to cycle on different winter cycling conditions shown in photos and the rolling resistance level measured on the same conditions.

The stated cycling willingness drops significantly with increasing bicycle rolling resistance. The cycling willingness index $(\mathrm{CWI})$, indicating the percentage of people being positive to cycle on the shown conditions, dropped from $91.2 \%$ at coefficients of rolling resistance (Crr) lower than 0.01 to $18.3 \%$ at a Crr larger than 0.05 . The CWI dropped rapidly from very low $(<0.01)$ to low (0.01-0.02) rolling resistances, whereas from high (0.03$0.04)$ to very high (>0.05) rolling resistances, the CWI dropped at a slower rate. All frequent and occasional winter cyclists had a high CWI on very low rolling resistances.
How rapidly the CWI drop due to increasing rolling resistances depends on the cyclists' age and gender, the winter climate they are familiar with, their winter cycling experience and habits, and whether they use studded tires when cycling during the winter.

Surprisingly, e-bike users are no less affected by increasing rolling resistances due to snow and ice than users of standard bicycles. This finding indicates that cycling willingness is more governed by the feeling of safety rather than the physical effort needed to overcome an increased rolling resistance. Increased rolling resistance under winter conditions is accompanied by reduced steerability and increased unevenness, leading to a reduced feeling of safety when cycling.

To increase the number of winter cyclists, continuous, long-term efforts are required because the winter cycling experience makes cycling willingness robust to increasing rolling resistances from snow and ice on the roads. Smaller efforts may keep or increase the winter cycling frequency of existing winter cyclists.

The use of studded tires has a significant positive effect on people's cycling willingness under winter conditions.

This study's findings show that bicycle rolling resistance measurements are well-suited for quantifying the surface quality on cycleways under winter conditions. The rolling resistance level can be used to estimate the cycling willingness index for different user groups, and the bicycle-infrastructure winter-resilience.

By comparing the results from this study to the cost of maintaining different rolling resistance levels on cycleways during winter, we could come one step closer to evaluate the cost-benefit of improved winter maintenance on cycleways.

\section{Abbreviations}

$\mathrm{C}_{\mathrm{rr}}$ : Coefficient of rolling resistance; CWl: Cycling willingness index

\section{Acknowledgements}

The authors particularly wish to thank the valuable expert input they received from Katja Skille and Bård Nonstad (NPRA).

\section{Authors' contributions}

All authors participated in designing the study. MDF collected and analyzed the rolling resistance data and the data from the online survey and was a major contributor in writing the manuscript. All authors read and approved the final manuscript.

\section{Authors' information}

AKP is a professor and MDF is a PhD candidate at the Winter Maintenance Research Centre at NTNU Norwegian University of Science and Technology. This study is a part of the NPRA research program BEVEGELSE. The overall goal with BEVEGELSE is to increase the number of pedestrians and cyclists with better winter maintenance.

\section{Funding}

This study was funded by the Norwegian Public Roads Administration (NPRA) through the research project "BEVEGELSE". NPRA participated in designing the study. NPRA did not participate in the collection, analysis, or interpretation of data or in writing the manuscript. 


\section{Availability of data and materials}

The datasets generated and/or analyzed during the current study are available in the Mendeley Data repository, https://doi.org/10.17632/ h3rc7973fx.1 [17].

\section{Declarations}

\section{Ethics approval and consent to participate}

Not applicable.

\section{Consent for publication}

Not Applicable.

\section{Competing interests}

The authors declare that they have no competing interests.

Received: 5 February 2021 Accepted: 17 March 2021

Published online: 23 April 2021

\section{References}

1. AaltoSetälä N et al (2017) Bicycle account 2017. Helsinki City Planning Department Retrieved from https://www.hel.fi/hel2/ksv/julkaisut/esitteet/ esite_2017-3-en.pdf

2. Abbott-Chapman J, Denholm C, Wyld C (2007) Gender differences in adolescent risk taking: are they diminishing?: an Australian intergenerational study. Youth Soc 40(1):131-154. https://doi.org/10.1177/0044118X07309206

3. Amiri M, Sadeghpour F (2015) Cycling characteristics in cities with cold weather. Sustain Cities Soc 14:397-403. https://doi.org/10.1016/j.scs.2013.11. 009

4. An R, Zahnow R, Pojani D, Corcoran J (2019) Weather and cycling in New York: the case of Citibike. J Transp Geogr 77:97-112. https://doi.org/10.1016/ j.jtrangeo.2019.04.016

5. Baldissera P, Delprete C (2016) Rolling resistance, vertical load and optimal number of wheels in human-powered vehicle design. Proc Inst Mech Eng P J Sport Eng Technol 231(1):33-42. https://doi.org/10.1177/175433711562 5002

6. Bergström A, Magnusson R (2003) Potential of transferring car trips to bicycle during winter. Transp Res A Policy Pract 37(8):649-666. https://doi. org/10.1016/S0965-8564(03)00012-0

7. Blondiau T, van Zeebroeck B, Haubold H (2016) Economic benefits of increased cycling. Transp Res Procedia 14:2306-2313. https://doi.org/10.101 6/j.trpro.2016.05.247

8. Brandenburg C, Matzarakis A, Arnberger A (2007) Weather and cycling-a first approach to the effects of weather conditions on cycling. Meteorol Appl 14(1):61-67. https://doi.org/10.1002/met.6

9. Butterworth E, Pojani D (2018) Why isn't Australia a cycling mecca? Eur Transp 69(69)Paper n4. http://www.istiee.unict.it/issues/69-2018.

10. Byrnes JP, Miller DC, Schafer WD (1999) Gender differences in risk taking: a meta-analysis. Psychol Bull 125(3):367-383. https://doi.org/10.1037/0033-2 909.125.3.367

11. Clark SK (1978) Rolling resistance of pneumatic tires. Tire Sci Technol 6(3): 163-175. https://doi.org/10.2346/1.2151003

12. Clark, S. K., \& Dodge, R. N. (1979). A handbook for the rolling resistance of pneumatic tires. Retrieved from https://deepblue.lib.umich.edu/handle/202 $7.42 / 4274$

13. Descornet G (1990) Road-surface influence on tire rolling resistance. In: Surface characteristics of roadways: international research and technologies, pp 401-415

14. Dunn OJ (1964) Multiple comparisons using rank sums. Technometrics 6(3): 241-252. https://doi.org/10.2307/1266041

15. Ellis, I. O., et al. (2016). Utvikling og variasjon i sykkelomfanget i Norge - En dybdeanalyse av den norske reisevanundersøkelsen. Retrieved from https:// vegvesen.brage.unit.no/vegvesen-xmlui/handle/11250/2679638

16. Fenre MD, Klein-Paste A (2020a) Bicycle rolling resistance measurements and video recordings under winter conditions in Trondheim 2019. Mendeley Data V1. https://doi.org/10.17632/gd9hjw997f.1

17. Fenre MD, Klein-Paste A (2020b) Winter cycling survey including photos of road conditions and rolling resistance data (In Norwegian). Mendeley Data V1. https://doi.org/10.17632/h3rc7973fx.1
18. Fenre MD, Klein-Paste $A$ (2021) Rolling resistance measurements on cycleways using an instrumented bicycle. J Cold Reg Eng 35(2):04021001. https://doi.org/10.1061/(ASCE)CR.1943-5495.0000244

19. Fenre MD, Klein-Paste $A$ (2021) Bicycle rolling resistance under winter conditions. Cold Reg Sci Technol 187 https://doi.org/10.1016/j.coldregions.2 021.103282

20. Fishman E, Schepers P, Kamphuis CBM (2015) Dutch cycling: quantifying the health and related economic benefits. Am J Public Health 105(8):e13-e15. https://doi.org/10.2105/AJPH.2015.302724

21. Flynn BS, Dana GS, Sears J, Aultman-Hall L (2012) Weather factor impacts on commuting to work by bicycle. Prev Med 54(2):122-124. https://doi.org/10.1 016/j.ypmed.2011.11.002

22. Fournier N, Christofa E, Knodler MA Jr (2017) A sinusoidal model for seasonal bicycle demand estimation. Transp Res Part D Transp Environ 50: 154-169. https://doi.org/10.1016/j.trd.2016.10.021

23. Gatersleben B, Appleton KM (2007) Contemplating cycling to work: attitudes and perceptions in different stages of change. Transp Res A Policy Pract 41(4):302-312. https://doi.org/10.1016/j.tra.2006.09.002

24. Gent AN, Walter JD (2006) Pneumatic tire. Mechanical Engineering Faculty Research, The University of Akron p 854. Retreived from The University of Akron, Ohio: https://ideaexchange.uakron.edu/mechanical_ideas/854/

25. Gillespie TD (1992) Fundamentals of vehicle dynamics, vol 400 . Society of Automotive Engineers, Warrendale. https://doi.org/10.4271/R-114

26. Godavarthy RP, Rahim Taleqani A (2017) Winter bikesharing in US: user willingness, and operator's challenges and best practices. Sustain Cities Soc 30:254-262. https://doi.org/10.1016/j.scs.2017.02.006

27. Heesch KC, Sahlqvist S, Garrard J (2012) Gender differences in recreational and transport cycling: a cross-sectional mixed-methods comparison of cycling patterns, motivators, and constraints. Int J Behav Nutr Phys Act 9(1): 106. https://doi.org/10.1186/1479-5868-9-106

28. Heinen E, van Wee B, Maat K (2010) Commuting by bicycle: an overview of the literature. Transp Rev 30(1):59-96. https://doi.org/10.1080/014416409031 87001

29. Huttunen R (2017) Finlands energy and climate strategy for 2030 (in Finnish). Ministry of Economic Affairs and Employment Retrieved from http://urn.fi/URN:ISBN:978-952-327-190-6

30. Koska, T., \& Rudolph, F. (2016). The role of walking and cycling in reducing congestion : a portfolio of measures. Retrieved from Wuppertal Institut: https://epub.wupperinst.org/frontdoor/index/index/docld/6597

31. Kruskal WH, Wallis WA (1952) Use of ranks in one-criterion variance analysis. J Am Stat Assoc 47(260):583-621. https://doi.org/10.2307/2280779

32. Lidström M (1979)Aircraft rolling resistance in loose dry snow: a theoretical analysis. Statens Väg-och Trafikinstitut Report nr 173A. Retreived from Swedish National Road and Transport Research Institute: http://vti.diva-porta l.org/smash/get/diva2:674319/FULLTEXT01.pdf

33. Litman $T$ (2020) Pandemic-resilient community planning. Retrieved from Victoria Transport Policy Institute: https://www.vtpi.org/PRCP.pdf

34. Malone, K. (2020). Smart choices for cities: cycling in the city. Retrieved from CIVITAS: https://ec.europa.eu/transport/sites/transport/files/cycling-guidance/ smart_choices_for_the_city_cycling_in_the_city_0.pdf

35. Mann HB, Whitney DR (1947) On a test of whether one of two random variables is stochastically larger than the other. Ann Math Stat 18(1):50-60 Retrieved from http://www.jstor.org/stable/2236101. https://doi.org/1 $0.1214 /$ aoms/1177730491

36. Nahal T, Mitra R (2018) Facilitators and barriers to winter cycling: case study of a downtown university in Toronto, Canada. J Transp Health 10:262-271. https://doi.org/10.1016/j.jth.2018.05.012

37. Niska A (2010) The importance of winter maintenance for cyclists. In: Paper presented at the 13th PIARC international winter road congress, Quebec, Canada

38. Niska A et al (2014) Skid resistance - important for bike safety. In: Paper presented at the international cycling safety conference, Gothenburg, Sweden

39. NMTC (2018) National transport plan 2018-2029 (English summary). Norwegian Ministry of Transport and Communications Retrieved from https:// www.regieringen.no/en/dokumenter/meld.-st.-33-20162017/id2546287/

40. Nordström, T., et al. (2014). Oslo cyclist. Mapping of present and future cyclists. Basis report for cycling strategy in Oslo 2015-2025 (in Norwegian). Retrieved from Oslo Municipality: https://www.sykkelbynettverket.no/fag/fa glitteratur/planlegging/_attachment/1145262?_download=true\&_ts=1523f4 b4ac8 
41. Norwegian Public Roads Administration (NPRA). (2019). Nasjonalt regnskap for bærekraftig mobilitet 2018 ("Norwegian sustainable transportation report 2018") (in Norwegian). Retrieved from www.sykkelbynettverket.no: https:// www.sykkelbynettverket.no/fag/faglitteratur/sykkelregnskap/_attachment/2 745504?_download=true\&_ts=16bbc09bbf8

42. Orvin MM (2020) Bicyclists' travel behavior analysis: modeling bicycling demand, speed choice, destination choice, and usage of shared mobility services. The University of British Columbia. https://doi.org/10.14288/1.0389954

43. Parkin J, Wardman M, Page M (2007) Models of perceived cycling risk and route acceptability. Accid Anal Prev 39(2):364-371. https://doi.org/10.1016/ j.aap.2006.08.007

44. Pucher J, Buehler R (2012) City cycling. The MIT Press, Cambridge. https:// doi.org/10.7551/mitpress/9434.001.0001

45. Schneider RJ (2013) Theory of routine mode choice decisions: an operational framework to increase sustainable transportation. Transp Policy 25:128-137. https://doi.org/10.1016/j.tranpol.2012.10.007

46. Sears J, Flynn BS, Aultman-Hall L, Dana GS (2012) To bike or not to bike: seasonal factors for bicycle commuting. Transp Res Rec 2314(1):105-111. https://doi.org/10.3141/2314-14

47. SMEl (2017) A national cycling strategy for more and safer cycling (English fact sheet). Swedish Ministry of Enterprise and Innovation Retrieved from https://www.government.se/49e190/contentassets/cff15923ae5848a3862 80eaa9d3e3c2e/20170608_faktablad_cykelstrategi_eng_webb-2.pdf

48. Spencer P, Watts R, Vivanco L, Flynn B (2013) The effect of environmental factors on bicycle commuters in Vermont: influences of a northern climate. J Transp Geogr 31:11-17. https://doi.org/10.1016/j.jtrangeo.2013.05.003

49. Sun G, Zacharias J (2017) Can bicycle relieve overcrowded metro? Managing short-distance travel in Beijing. Sustain Cities Soc 35:323-330. https://doi.org/10.1016/j.scs.2017.08.010

50. Svorstøl E-T et al (2017) Drift og vedlikeholds betydning for gående og syklende: En kunnskapsoppsummering [The effect of maintenance operations on pedestrians and cyclists. A litterature review], p 99 [In Norwegian]. Retrieved from Norwegian Public Roads Administration: http:// hdl.handle.net/11250/2633497

51. Sørensen, M. W. J., \& Mosslemi, M. (2009). Subjective and objective safety the effect of road safety measures on subjective safety among vulnerable road users (1009/2009). Retrieved from Norwegian Centre for Transport Research - Institute of Transport Economics: https:/www.toi.no/getfile. php?mmfileid $=11739$

52. Teschke K et al (2012) Bicycling: health risk or benefit. UBC Med J 3(2):6-11

53. The Norwegian Meteorological Institute. (2020). Weather observations. Retrieved from http://www.senorge.no

54. van Es GWH (1999) Method for predicting the rolling resistance of aircraft tires in dry snow. J Aircr 36(5):762-768

55. Veisten, K., et al. (2019). Economic analysis of measures for improved operation and maintenance for cycling and walking (1690/2019). Retrieved from Norwegian Public Roads Administration: http://hdl.handle.net/11250/2633492

56. Willis DP, Manaugh K, el-Geneidy A (2015) Cycling under influence: summarizing the influence of perceptions, attitudes, habits, and social environments on cycling for transportation. Int J Sustain Transp 9(8):565579. https://doi.org/10.1080/15568318.2013.827285

57. Xu G, Sturges L, Chapman M, Albrecht C, Bergner D, Shi X (2017) Snow removal performance metrics: past, present, and future. Transp Res Rec 2613(1):61-70. https://doi.org/10.3141/2613-08

\section{Publisher's Note}

Springer Nature remains neutral with regard to jurisdictional claims in published maps and institutional affiliations. 